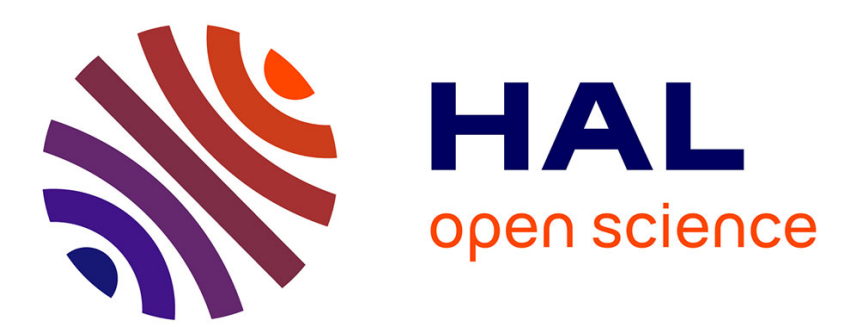

\title{
The Black-Scholes model as a determinant of the implied volatility smile: A simulation study
}

\author{
Gianluca Vagnani
}

\section{To cite this version:}

Gianluca Vagnani. The Black-Scholes model as a determinant of the implied volatility smile: A simulation study. Journal of Economic Behavior and Organization, 2009, 72 (1), pp.103. 10.1016/j.jebo.2009.05.025 . hal-00736952

\section{HAL Id: hal-00736952 \\ https://hal.science/hal-00736952}

Submitted on 1 Oct 2012

HAL is a multi-disciplinary open access archive for the deposit and dissemination of scientific research documents, whether they are published or not. The documents may come from teaching and research institutions in France or abroad, or from public or private research centers.
L'archive ouverte pluridisciplinaire HAL, est destinée au dépôt et à la diffusion de documents scientifiques de niveau recherche, publiés ou non, émanant des établissements d'enseignement et de recherche français ou étrangers, des laboratoires publics ou privés. 


\section{Accepted Manuscript}

Title: The Black-Scholes model as a determinant of the implied volatility smile: A simulation study

Author: Gianluca Vagnani

PII: $\quad$ S0167-2681(09)00166-8

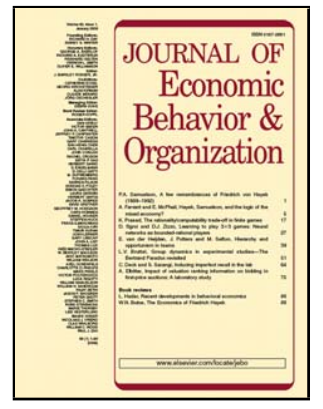

DOI: $\quad$ doi:10.1016/j.jebo.2009.05.025

Reference: $\quad$ JEBO 2411

To appear in: Journal of Economic Behavior \& Organization

Received date: $\quad 21-5-2007$

Revised date: 28-5-2009

Accepted date: $\quad$ 28-5-2009

Please cite this article as: Vagnani, G., The Black-Scholes model as a determinant of the implied volatility smile: A simulation study, Journal of Economic Behavior and Organization (2008), doi:10.1016/j.jebo.2009.05.025

This is a PDF file of an unedited manuscript that has been accepted for publication. As a service to our customers we are providing this early version of the manuscript. The manuscript will undergo copyediting, typesetting, and review of the resulting proof before it is published in its final form. Please note that during the production process errors may be discovered which could affect the content, and all legal disclaimers that apply to the journal pertain. 


\title{
The Black-Scholes model as a determinant of the implied volatility
} smile: A simulation study

\author{
Gianluca Vagnani \\ Sapienza, University of Rome, Faculty of Economics \\ Department of Business Management \\ 00161, Castro Laurenziano, Rome, Italy \\ gianluca.vagnani@uniroma1.it
}




\title{
The Black-Scholes model as a determinant of the implied volatility smile: A simulation study
}

\begin{abstract}
The paper represents an initial effort to shed light on the determinants of the implied volatility smile in financial (derivative) markets. It fully details the implications of the institutionalization of the Black-Scholes model in an uncertain world populated by individuals who are bounded by the amount of calculation or accounting which is technically possible. Combining model simulations, empirical analysis, and mathematical derivations, the paper proposes that the determinants of the volatility smile might be related to the behavior of traders. In pricing options, they use the widely accepted Black-Scholes formula with a measure of stock volatility that they derive from their subjective beliefs. Moreover, heterogeneity of traders' beliefs and the way traders update their expectations have nontrivial effects, both on equilibrium prices and on the emergence of the implied volatility smile.
\end{abstract}

Key words: implied volatility smile; Black-Scholes option pricing model; agent-based simulation.

\section{Introduction}

This paper stands at the frontier between the academic disciplines of finance and organization theory. It concerns finance, generally, by addressing the long-standing problem of pricing financial options and, specifically, the phenomenon of the implied volatility smile. It concerns organizational theory because the emergence of the implied volatility smile, we argue, might be related to the behavior of boundedly rational individuals who-equipped with the widely accepted formula of Black and Scholes (1973) - try to resolve the uncertainty about future underlying stock volatility, in part by learning from the flow of information the market provides and in part by relying on their subjective beliefs.

A standard financial option gives its owner the right to buy or sell some asset in the future for a fixed price (the strike price). Call options confer the right to buy the asset, while put options confer the right to sell the asset. These rights can be exercised at a predefined point in time (European option) or at any time before the expiry date (American option). In both kinds of options, the implied volatility is the value the market has implicitly assigned to the option, which, in turn, justifies its current market price. In other words, it is the volatility value that 
creates the theoretical value for the option, as derived by a particular pricing model, identical to the current market price.

Using the Black-Scholes (1973) option pricing model, if we plot the implied volatility as a function of the exercise price, we should obtain a horizontal straight line. This implies that all options for buying or selling the same underlying asset with the same expiration date, but with different exercise prices, should have the same implied volatility. This is not, however, what occurs in practice in option markets worldwide. The implied volatility presents a strong Ushaped pattern, as the call option goes from deep in-the-money to at-the-money and then to deep out-of-the-money, or as the put option goes from deep out-of-the-money to at-the-money and then to deep in-the-money (e.g., Black, 1975; MacBeth and Merville, 1979; Galai, 1983; Rubinstein, 1985; Derman and Kani, 1994). In addition, the U-shaped pattern is most pronounced for short-term options, with the graph of the implied volatility function looking like the smile of the "Cheshire cat" (e.g., Cont and da Fonseca, 2002).

The research that has studied the volatility smile (or volatility skew) is abundant, and several approaches have been proposed both to explain and to model it. In a prominent work, Rubinstein (1994) related the smile effect to the presence of (i) jumps in the price of the underlying asset between successive opportunities to trade, (ii) market imperfections and frictions, such as transaction costs, illiquidity, and other trading restrictions, which imply that a single arbitragefree option price no longer exists, and (iii) disturbances in the price process of the underlying assets that do not follow a geometric Brownian motion with constant volatility. Regarding the presence of jumps in the price of the underlying asset, Hafner and Wallmeier (2001) analyzed the determinants of the volatility smile in the Danish financial markets and indicated that market participants' assessment of crash risk does affect the smile. It follows that traders set the expected volatility value artificially, at a level that is higher than the historical one, in order to obtain a risk premium against an unexpected decrease (for in-the-money options) or increase (for out-of-the-money options) of the stock price. Regarding the presence of market imperfections and frictions, Longstaff (1995) and Figlewski (1989) examined the effects of transaction costs and found that they could be a major element in the divergences of implied volatilities across 
strike prices. Furthermore, Constantinides (1997) stated that transaction costs affect the equilibrium asset prices and, therefore, generate a difference in the mean rate of return of two assets, one of which is subjected to transaction costs, and the other, not. Thus, the concept of a single, no-arbitrage price of a derivative is replaced by a range of option prices that may differ across strike rates. On the presence of disturbances in the price process, it is assumed that skewness and excess kurtosis in the underlying asset return distributions are the main sources of the volatility smile in option prices because they make extreme observations more likely than the value predicted by the Black-Scholes model, and, in turn, they increase the value of away-fromthe-money options relative to at-the-money options (e.g., Hull, 1993).

Models attempting to incorporate stochastic volatility processes are varied. Among them, we refer to the stochastic volatility models (Hull and White, 1987), the general equilibrium stochastic volatility models (Detemple and Osakwe, 2000), the pure jump-diffusion models (Merton, 1976), the affine jump-diffusion models (Duffie et al., 2000), and the double exponential jump-diffusion models (Kou, 2002). In particular, it has been demonstrated that stochastic volatility models exhibit a symmetric smile locally centered on the current forward price, as originally shown by Renault and Touzi (1996). A simpler proof can also be found in Sircar and Papanicolaou (1999). The authors show the result by Renault and Touzi (1996) noting that if the stochastic volatility stems from a diffusion process driven by a Brownian motion uncorrelated with the Brownian motion driving the stock price, and the option price is computed by means of the so-called Hull and White formula (which is an expectation of the Black-Scholes price), then the implied volatility is locally convex and symmetric around the current forward price. Unable to account for the case wherein low-strike implied volatilities are higher than highstrike implied volatilities, stochastic volatility models have been enriched by introducing a more articulated and complex form of the volatility. In a prominent contribution, Brigo and Mercurio (2002) propose a model in which the volatility is correlated with the stock price. By doing so, the authors were able to construct a model that lead to skews in the form of the implied volatility. From a different perspective, Ziegler (2002) observed that under heterogeneous beliefs about the true mean of the constant instantaneous increase in expected dividends, which is another 
parameter of the Black-Scholes option pricing model, the state-price density function is not log normal. As a consequence, the non-log-normality of the equilibrium state-price density gives rise to a volatility smile. Furthermore, the implied volatility curve becomes steeper and tends to assume a skewed U-shape as the degree of heterogeneity in beliefs is increased (on the importance of heterogeneity of traders in asset markets, see also Li and Rosser, 2001).

Although we recognize the undisputed contribution of these studies, we must observe that traditional research on the volatility smile has been based on the development and analysis of highly stylized, analytically tractable models, in which traders' limits in knowledge or foresight, heterogeneity of beliefs, and learning mechanisms may be or are sometimes missing (e.g., for a review of option pricing models, see Broadie and Detemple, 2004). On the other hand, it may be a difficult task to enrich and even to refine the assumptions beyond the Black-Scholes model in order to endogenize the volatility smile because the Black-Scholes model itself is the basic cause of the volatility smile. In this sense, borrowing from Callon (1998) and MacKenzie and Millo (2003), the Black-Scholes model does not describe an existing external financial market, but rather brings that market into being: the Black-Scholes model performs the functions of the financial market, creating an artificial state of affairs in which there is a substantive orientation, effectively enforced by the provision of an order, on the way actors behave. Therefore, the Black-Scholes model performs a sort of regulation of the market itself, with traders adapting themselves to it.

The present work is an attempt to flesh out what we believe to be some essential elements that explain the volatility smile and to provide a framework that links these elements to theory at the market level of analysis. In part, this requires making more explicit what is already implicit in some works on the problem, such as the mathematical formulation of the Black-Scholes model (e.g., Rubinstein, 1994; Renault and Touzi, 1996; Sircar and Papanicolaou, 1999). In part, it involves new considerations and, specifically, it asks us to reframe the problem posed by the presence of the implied volatility smile as less of a mathematical problem of how to model a stock volatility that is stochastic, and more a taking into account of both the role of traders' beliefs and the environment in which these beliefs are formed and updated over time. 
We will therefore adopt a research approach combining model simulations, empirical analysis, and mathematical derivations. We propose a computational model using agent-based simulation techniques. It must be observed that our intent is to link the emergence of the implied volatility smile to certain rules of thumb followed by autonomous, heterogeneous, and adaptive traders in pricing options. These features (bounded rationality, heterogeneity, and learning) appear to be best handled by computation. Agent-based computational models permit us to address such features and constitute a powerful research method for theory development based on more realistic assumptions than closed-form solutions (Cohen and Cyert, 1965). As was recently observed by Dawid and Fagiolo (2008), by explicitly modeling the decentralized interaction of heterogeneous economic agents in systems such as markets, industries, or organizations, agent-based computational economics attempts to transcend the numerous oversimplifying assumptions underlying most mainstream analytical models. Moreover, unlike empirical analyses, which are very data intensive and pose problems of adequately controlling for competing arguments, a simulation permits us to create a controlled environment, in which traders' beliefs and learning algorithms are transparent and can be carefully controlled and modified (see Holland and Miller, 1991; Roth, 2002; Tesfatsion and Judd, 2006). Thus, it allows us to test whether our logic works in principle by eliminating all alternative explanations. We then perform an empirical analysis on S\&P 500 index options to assess model robustness. The results of this analysis conform very well to the simulation results. Finally, as already observed, an exact analysis of the phenomenon studied here is very difficult to obtain because of the highly nonlinear nature of agents' behaviors and interactions over time. However, using a greatly simplified model that retains the essential properties of interest, we mathematically adduce the emergence of the implied volatility smile from the way individuals seek to resolve the uncertainty surrounding a stock's volatility. Analytical results proposed in Appendix A confirm that the volatility observed is induced by behaviors that are, in turn, encouraged by the techniques traders are accustomed to using when dealing with option pricing. 


\section{Model}

Our model simulates a financial (derivative) market, in which $J$ European call options are traded with the time to maturity $T$ and the strike price $K_{j}>0$, where $j$ belongs to a finite set $J$. All call options are written on only one underlying risky asset, say $S=\left\{S_{t}\right\}_{t}$ with $S_{0}=s$; we denote by $\widetilde{C}(K)=\left\{\widetilde{C}_{t}(K)\right\}_{t}$ the market equilibrium price of the European call option with strike price $K$. Our model is completed by considering the safe asset $B$, paying a fixed real dividend $r$, the riskless rate. ${ }^{1}$

At any time $\tau \in[0, T]$, each trader can choose to change her strategy. In other words, at time $\tau$, a buyer chooses to sell her holdings and a seller chooses to buy options. We also introduce $\omega_{i, 0}$ as the $i$ trader's wealth at initial time zero, for $i=1, \ldots, N(K)$, where $N(K)$ is the number of traders that deal with the call option with the strike price $K$. Given $\lambda_{i}(K)$ the amount of the European call option, with strike price $K$, that agent $i$ holds in the period $[0, \tau)$, and $\lambda_{i}=\left(\lambda_{i}(K), j \in J\right)$, we denote the $i^{t h}$ trader's wealth at time $\tau$ by

$$
\omega_{i, \tau}=\sum_{j \in J} \lambda_{i}\left(K_{j}\right) \cdot \widetilde{C}_{\tau}\left(K_{j}\right)+e^{r \tau}\left[\omega_{i, 0}-\sum_{j \in J} \lambda_{i}\left(K_{j}\right) \cdot \widetilde{C}_{0}\left(K_{j}\right)\right]
$$

As in the Santa Fe Institute Artificial Stock Market model (see De Long et al., 1990; Palmer et al., 1994; Arthur et al., 1997; LeBaron et al., 1999; Ehrentreich, 2006), our trader's aim is to maximize $\widehat{E}_{i, 0}\left[\omega_{i, \tau}(\lambda)\right]-\gamma_{i} \widehat{\operatorname{Var}}_{i, 0}\left(\omega_{i, \tau}(\lambda)\right)$, where $\widehat{E}_{i, t}$ denotes the expectation of trader $i$ conditional on information up to time $t, \gamma_{i}$ is the coefficient of absolute risk aversion, and, for a given random variable $X, \widehat{\operatorname{Var}}_{i, 0}$ is the variance of $X$ with respect to $\widehat{E}_{i, t}$. These mean variance criteria correspond, in the Gaussian case, to the maximum of a utility function, such as $U_{i}(x)=-e^{-2 \gamma_{i} x}$ (see Freund, 1956).

\footnotetext{
${ }^{1}$ We concentrate our attention on European options, because their prices and their derived implied volatility functions are key to price other derivative securities. As observed by Fouque et al. (2001), European options prices, encapsulated in the skew surface, are part of the basic observables and, in turn, any effort to understand the determinants of the implied volatility smile for European options might also contribute to the stochastic volatility literature on other kinds of options.
} 
In the proposed model, each trader invests all of her limited funds in one option; this is to say that the $i^{\text {th }}$ trader deals with only the call option with strike price $K_{j}$ for a $j=j(i)$. In other words, we have that $\lambda_{i}\left(K_{j}\right)=0$ except for $j=j(i)$. Therefore, traders' maximization of (1) becomes equivalent to maximizing, for $K=K_{j(i)}$,

$$
\lambda_{i}(K)\left[\widehat{C}_{i, \tau}(K)-e^{r \tau} \widetilde{C}_{0}(K)\right]-\gamma_{i} \cdot\left[\lambda_{i}(K)\right]^{2} \cdot \delta_{i, \tau}(K)
$$

where $\widehat{C}_{i, \tau}(K):=\widehat{E}_{i, 0}\left[\widetilde{C}_{\tau}(K)\right]$ and $\delta_{i, \tau}(K):=\widehat{\operatorname{Var}}_{i, 0}\left(\widetilde{C}_{\tau}(K)\right)$ is the variance of traders' expectations on $\widetilde{C}_{\tau}(K)$, according to the beliefs of trader $i$.

The maximum in (2) is achieved with

$$
\lambda_{i}^{*}(K)=\frac{1}{2 \gamma_{i}} \frac{\widehat{C}_{i, \tau}(K)-e^{r \tau} \widetilde{C}_{0}(K)}{\delta_{i, \tau}(K)}=\frac{e^{r \tau}}{2 \gamma_{i}} \frac{\bar{C}_{i, \tau}(K)-\widetilde{C}_{0}(K)}{\delta_{i, \tau}(K)}
$$

where $\bar{C}_{i, \tau}(K)=e^{-r \tau} \widehat{C}_{i, \tau}(K)$. Setting for every $K \in\left\{K_{j}, j \in J\right\}$ the amount of the call option to a given fixed value of 1 , which means that in equilibrium

$$
\sum_{i=1}^{N} \lambda_{i}^{*}(K)=1
$$

Given that the aggregate demand is linear in $\widetilde{C}_{0}(K)$, we explicitly derive the solution of the above equation for an equilibrium price:

$$
\widetilde{C}_{0}(K)=\frac{1}{N}\left[\sum_{i=1}^{N} \bar{C}_{i, \tau}(K)-2 \cdot e^{-r \tau} \sum_{i=1}^{N} \gamma_{i} \delta_{i, \tau}(K)\right]
$$

Eq. (3) expresses the equilibrium option price at time 0 as a function of $\bar{C}_{i, \tau}(K)$, the expected option prices at time $\tau$, the behavioral parameter of the model $\gamma_{i}$, and the second moment of the $\tau$-period-ahead distribution of expected option prices $\delta_{i, \tau}(K)$. It also must be observed that the equilibrium market price is assumed to be outside the control of traders. In our model, each agent forms an expectation on the equilibrium price at time $\tau$, and then she determines her demands for the option in question at time 0 . Given the fixed supply normalized to 1 , a specialist collects all demands and, according to Eq. (3), sets the price to clear the market and at such an equilibrium price, no agent would want to change her actions. We notice that this simple 
Walrasian auctioneer process for handling market clearing has the advantage that results are not influenced by any troubling issue with pricing adjustment or by any ad hoc mechanism that might artificially create higher demand for some options (e.g., options close-to-the-money) and, in turn, forces the emergence of the implied volatility smile (see LeBaron et al., 1999; Ehrentreich, 2006). However, alternative modeling of market clearing rules and their effect on the emergence of the implied volatility smile is an important extension that needs to be addressed in future studies.

To complete our market model description, we need only to specify how traders compute their expected option prices. In this regard, our economy is populated by noise traders in proportion $\theta$ and by "Black-Scholes traders" in proportion $1-\theta$.

Noise traders are individuals who perceive the expected prices of the call option as an independent and identically distributed random variable. Accordingly, noise traders define the option price as $\bar{C}_{i, \tau}(K) \sim N\left(C_{i}(K)^{*}, \sigma_{C_{i}(K)}^{2}\right)$, where $C_{i}(K)^{*}$ is the average price of the option as expected by trader $i$ and $\sigma_{C_{i}(K)}^{2}$ is the variance of trader's expectations (see De Long et al., 1990).

Black-Scholes traders assume (implicitly or explicitly) that the underlying asset price follows a geometric Brownian motion, with constant stochastic volatility, $S_{t}=s \exp \left\{\left(r-\Sigma^{2} / 2\right) t+\Sigma W_{t}\right\}$, where $W_{t}$ is a Brownian motion, independent of the stochastic volatility $\Sigma$. Therefore, the equilibrium market price at time $\tau$ can be computed according to the well-known Black-Scholes formula, that is, $\widetilde{C}_{\tau}(K)=C^{B . S .}\left(S_{\tau}, r, T-\tau, K, \Sigma\right)$, where

$$
C^{B . S .}\left(S_{\tau}, r, T-\tau, K, \Sigma\right)=S_{\tau}\left[\Phi\left(\frac{l(K)}{v \sqrt{T-\tau}}+\frac{v \sqrt{T-\tau}}{2}\right)-e^{-l(K)} \Phi\left(\frac{l(K)}{v \sqrt{T-\tau}}-\frac{v \sqrt{T-\tau}}{2}\right)\right]
$$

and $l(K)=l\left(S_{\tau}, r, T-\tau, K\right)=\ln \left(S_{\tau} e^{r(T-\tau)} / K\right)$. As a consequence, we have that:

$$
\begin{aligned}
\widetilde{C}_{\tau}(K) & =E_{i}\left[\left(S_{T}-K\right)^{+} e^{-r(T-\tau)} \mid F_{\tau}^{S} \vee \sigma(\Sigma)\right] \\
& =E\left[\left(S_{\tau} \exp \left\{\left(r-v^{2} / 2\right)(T-\tau)+v\left(W_{T}-W_{\tau}\right)\right\}-K\right)^{+} e^{-r(T-\tau)}\right]_{v=\Sigma}
\end{aligned}
$$


We further assume that the current stock price $s$, the riskless interest rate $r$, and the time until option expiration $T$ are fixed and agreed upon by all traders, but that the stock volatility is not. It has been observed that

volatility forecasts are sensitive to the specification of the volatility model.... Correctly estimating the parameters of a volatility model can be difficult, because volatility is not observable [...and] volatility forecasts are anchored at noise proxies or estimates of the current level of volatility. Even with a perfectly specified and estimated volatility model, forecasts of future volatility inherit and potentially even amplify the uncertainty about the current level of volatility (Brandt and Jones, 2006: p. 470; see also Black, 1975).

Consequently, it is natural to believe that the option price is evaluated by traders $i$ as an expectation at time 0 for outcome at time $\tau$ under risk neutral measure. Therefore, for every $\tau \in[0, T]$ we have

$$
\bar{C}_{i, \tau}=e^{-r \tau} \widehat{C}_{i}(K):=e^{-r \tau} \int_{0}^{\infty} C^{B . S .}(s, r, T-\tau, K, v) F_{\Sigma_{i}}\{d v\}
$$

with $F_{\Sigma_{i}}$ the set of traders' beliefs (distribution function) over the possible values of stock volatility. Thus, Eq. (4) describes the behavior of boundedly rational agents who, far from being perfectly rational, rely on the Black-Scholes formula to price options and use a simple but reasonable rule of thumb (averaging) to resolve the uncertainty around the underlying stock volatility (e.g., Schelling, 1960; Arthur, 1994). ${ }^{2}$

\subsection{The simulation environment}

Built in Matlab 7 and borrowing from previous works on artificial stock markets (e.g., see Palmer et al., 1994; Arthur et al., 1997), the model we advance creates a dynamic system of high internal activity in which $J$ European call options with strike prices $K_{j}$ are on sale, and many bidders simultaneously submit their bids. In constructing their bids, traders use their subjective beliefs to resolve the uncertainty around the possible values of the stock volatility.

\footnotetext{
${ }^{2}$ As Keynes (1936) pointed out a long time ago: "Investment based on genuine long-term expectation is so difficult as to be scarcely practicable. He who attempts it must surely lead much more laborious days and run greater risks than he who tries to guess better than the crowd, how the crowd will behave" (p. 157).
} 
Computer simulation is the method of choice. As we have observed, it allows us to capture the whole complexity of the presented model within a single comprehensive framework and gives us the opportunity to follow it in action over an extended timeframe. All of our simulations begin with the assignment of a set of individual beliefs about the underlying stock volatility for each trader. From this point on, each simulation proceeds in cycles whereby each subsequent cycle is the next step. Given the current stock price, the riskless interest rate, and the time until the option expires, an option, with different strike prices $K$, is launched on the market. Traders evaluate the option characteristics, and taking into account their beliefs and their budget, simultaneously launch their offers. Thus, the demand schedule is composed, and, assuming the aggregate demand $\lambda_{t}$ to be equal to the fixed supply normalized to 1 , the market equilibrium price $\widetilde{C}_{0}(K)$ is derived according to Eq. (3). The implied volatility $\hat{\sigma}(K)$ is then extracted by inverting the Black-Sholes option price formula. Finally, payoffs are realized and the traders' wealth is updated.

In order to reduce the variance of our results, we use a common set of starting conditions and the same random seed for each run, that is, we simply reset the random number seed to its former, initial value before executing the next run with different values for the simulation parameters. In order to appreciate the stability of the model and to secure that the results are not merely specific realizations of a stochastic process, we also replicate each of these conditions 100 times. For each replication, we use different sets of random numbers drawn by using the same random seed (see Kleijnen, 1988; Conway et al., 1959). Results are then based on the average over 100 independent runs of the simulation model.

\section{The emergence of the implied volatility smile}

\subsection{The implied volatility smile in a typical simulation run}

The analysis starts by considering a homogeneous population of traders $(N(K)=100)$ that deals with a European call option with a strike price $K$ (ranging from 8 to 13), a current stock price $s$ (kept at 10), an average stock volatility (equal to 0.5 ), a risk-free rate $r$ (kept at 0.06 ), and a time-until-option expiration $T$ (kept at 1). Moreover, all traders have the same coefficient of 
absolute risk aversion $\gamma$ (kept at 0.8 ). Their expectations $F_{\Sigma_{i}}$ are modeled as a normal distribution, with its mean equal to 0.5 and its standard deviation equal to 0.05 . Moreover, we set at 0 the time at which a buyer sells her holdings. In our model, this implies that a trader buys an option at time $t$ to sell it at time step $t+1$. The average option price $C_{i}(K)^{*}$, as expected by noise traders, is drawn from a uniform distribution that ranges between 0.6 and 0.4 . This gives a two-dimensional parameter that yields 18 different experimental conditions.

In order to keep results of the different scenarios comparable, we make a transformation of the $(\sigma, K)$ axis. Movements in the underlying contract are measured on a logarithmic scale, and the relationship between the exercise price of an option and the current underlying price is expressed as the logarithm of the future price divided by the strike price. Thus, it makes sense to express the $x$-axis as $x=\ln \left(s e^{r T} / K\right)$. Furthermore, we still need to consider that the implied volatility may occupy different positions not only in two different scenarios but also in the same scenario at different time steps. In order to generalize the volatility scale $(y$-axis $)$, we then express all volatilities in terms of the volatility of a theoretical at-the-money option (i.e., $\left.y=\hat{\sigma}(K) / \hat{\sigma}\left(s e^{r T}\right)\right)($ see Natenberg, 1994).

Fig. 1 shows, on the normalized $(x, y)$ plane, that the implied volatility curve for the BlackScholes scenario $(\theta=0)$ has a striking congruence to a symmetric U-shaped function, with its minimum located in the neighborhood of the at-the-money point (i.e., the point at which $\left.K=s e^{r T}\right)$. On the contrary, if we turn to the noise scenario, the variance of the implied volatility data is considerably high, and the derived implied volatility curve tends to have an irregular shape. Moreover, it must be noticed that for values of $\theta$ between 0 and 0.60 , the resulting interpolating function still tends to resemble the U-shape. As soon as $\theta$ becomes greater than 0.67 , the U-shape vanishes. Therefore, the "smile" appears as an inevitable equilibrium outcome akin to a single basin of attraction, as long as a sufficient number of agents consists of BlackScholes traders. 
Insert Fig. 1 about here ${ }^{3}$

For the Black-Scholes scenario $(\theta=0)$, we further investigate the effect on the emergence of the implied volatility smile caused by the heterogeneity of traders' beliefs regarding the true stock volatility. Given the other parameters, experiments are then repeated by considering a market with moderate heterogeneity (i.e., average and standard deviation of traders' beliefs range uniformly across the population between 0.375 and 0.625 , and 0.0375 and 0.0625 ) extreme heterogeneity (i.e., average and standard deviation range uniformly between 0.125 and 0.875 , and 0.0125 and 0.0875 ), and a situation of very extreme heterogeneity (i.e., average and standard deviation of traders' beliefs range uniformly across the population between 0.125 and 4 , and 0.0125 and 0.0875$)^{4}$

Fig. 2 indicates that all the resulting curves are upward sloping and exhibit a curvature that is much higher for in-the-money options than for out-of-the-money options. Moreover, as the degree of heterogeneity in beliefs is increased, the curve becomes steeper, indicating a skew that becomes increasingly pronounced. But, it is interesting to note that as the level of heterogeneity passes from an extreme to a very extreme level, a gently asymmetric U-shape tends to appear (i.e., see curve 1 in Fig. 2). Because of the presence of abnormal expectations, many agents are driven out of the market, with only a few who remain and express a valid demand for the available option. Heterogeneity is then reduced and the implied volatility tends to regain a more symmetric shape. Therefore, the relation between the initial level of traders' heterogeneity and the magnitude of the skew in the implied volatility function is curvilinear, with the presence of a gently asymmetric U-shape that is likely to emerge in those markets in which traders tend to

\footnotetext{
${ }^{3}$ The data presented are taken at the 140th day after the option is launched and represent an average of 100 simulation runs. The solid line (1) represents the noise scenario; the dotted line (2) represents the BlackScholes scenario.

${ }^{4}$ Considering a European call option with a log-moneyness (kept at 0), a current stock price $s$ (kept at 10), a risk-free rate $r$ (kept at 0.06), and a time-until-option expiration $T$ (kept at 220), the difference between the highest and the lowest expected option price is equal to $\$ 0.614$ for the simulated scenario with a moderate level of heterogeneity; $\$ 1.839$ for the scenario with an extreme level of heterogeneity; and $\$ 7.565$ for the scenario with a very extreme level of heterogeneity. Note that for the S\&P 500 index options, in the period that extends from June 1, 1996, through May 31, 2000, the average bid-ask difference for at-the-money options is equal to $\$ 1.441$.
} 
have either almost the same or very distant and abnormal expectations about the underlying stock volatility.

Insert Fig. 2 about here ${ }^{5}$

Thus, as has been observed in the financial markets, the implied volatility presents strong Ushaped patterns, with the deepest in-the-money call-implied volatilities taking the highest values (e.g., Bakshi et al., 1997). From a theoretical point of view, it is also important to observe that the proposed model not only replicates the volatility patterns that have been observed in financial markets, but it relates the emergence of the implied volatility smile directly to the behavior of boundedly rational individuals who rely on their subjective beliefs to estimate the stock volatility and use these beliefs to price options according to the widely accepted Black-Scholes formula. This direct relationship remains without any explicit assumption on the correlation between the volatility and the stock price (e.g., Brigo and Mercurio, 2002), on the shape of the state-price density function, or of the underlying stock-volatility density function (e.g., Ziegler, 2002), and with the underlying stock volatility considered as the sole source of uncertainty.

\subsection{The adjustment of traders' beliefs over time}

The model also enables us to follow the dynamics of the volatility smile over time. Toward this aim, we allow the possibility that aspects of the model structure may change from time to time, as traders learn about the true stock volatility from information acquired from the surrounding environment (e.g., see Grossman and Stiglitz, 1980; Routledge, 1999; Barlevy and Veronesi, 2000). Arthur (1994) stated that "as feedback from the environment comes in, we may strengthen or weaken our beliefs in our current hypotheses, discarding some when they cease to perform, and replacing them as needed with new ones" (p. 407).

In formal terms, we propose that Black-Scholes traders react to the oncoming flow of information in terms of existing rules by employing a kind of belief-adjustment procedure that

\footnotetext{
${ }^{5}$ The data presented are taken at the 140th day after the option is launched and represent an average of 100 simulation runs. The long dashed line (1) represents a scenario with very extreme heterogeneity; the bold line (2), a scenario with moderate heterogeneity; the dotted line (3), a scenario with extreme heterogeneity.
} 
resembles that of a servomechanism often used in production control (Simon, 1957; see also Routledge, 1999). This is similar to the first-order response to experience that Cyert and March (1963) called the "problemistic search." At each time $t$, traders acquire from the market both the updated stock volatility $\sigma_{t}$ and the implied stock volatility $\hat{\sigma}_{t}(K)$, and, accordingly, revise their own beliefs about the value of the underlying stock volatility at time $t+1$ (see also Jean-Marie and Tidball, 2006). The following equation describes this behavior for trader $i$ :

$$
\sigma_{i, t+1}(K)=\sigma_{i, t}(K)+\xi^{1}\left(\hat{\sigma}_{t}(K)-\sigma_{i, t}(K)\right)+\xi^{2}\left(\sigma_{t}-\sigma_{i, t}(K)\right) \quad t=1, \ldots, T
$$

with $\hat{\sigma}_{t}(K)$ the implied volatility derived from the price of the option with the strike price $\mathrm{K}$ at time $t, \sigma_{t}$ the updated underlying stock volatility as evaluated by traders directly from stock market data at time $t$, and $\xi^{1}, \xi^{2}$ the adjustment factors. In this equation, $\sigma_{i, t}(K)$ is compared with both the implied volatility and the underlying stock volatility, and both are regarded as separate (i.e., the stock market is not influenced by the dynamics of the option market) and assumed to have a path that depends only on the aggregate behavior of the system. Their differences, then, are fed back into the Eq. (5) to alter the output in the direction of reducing the difference between traders' beliefs and market beliefs. From (5), we also see that a high (low) degree of $\xi^{1}$ and of $\xi^{2}$ is conducive to producing a relatively fast (slow) adjustment in traders' beliefs. In other words, at each stage, traders act from their beliefs; they detect a match or mismatch of outcome to expectation that confirms or refutes their beliefs. In the case of refutation, traders activate single-loop learning, since they move from error detection to error correction as proposed in Eq. (5).

Given the simulated data, for each combination of the two parameters $\xi^{1}$ and $\xi^{2}$ (that vary from 0 to 1 with steps of 0.01 ), holding the other parameters constant, we run a constrained, quadratic interpolation on the resulting implied volatilities over the considered levels of $K$, imposing the coefficient of the highest order to be greater than zero. We derive the parameters of the model, measure the R-squared value between the predicted and the observed data, and calculate the curvature, which indicates the extent to which the derived implied volatility curve tends to display a U-shape. 
Insert Fig. 3 about here ${ }^{6}$

Assuming moderate values for $\xi^{1}$ and $\xi^{2}$, and a moderate level of heterogeneity of traders' beliefs, Fig. 3 shows, on the normalized $(x, y)$ plane, how the passing of time affects the shape of the implied volatility curve. ${ }^{7}$ As soon as the expiration date is approached, we can see not only that the variance accounted for (i.e., R-squared) remains close to 1, the curvature increases, and the region of concavity around the moneyness shrinks (see Sircar and Papanicolaou, 1999), but also the curve tends to regain a symmetric U-shape. The latter effect holds in all except extreme levels of traders' heterogeneity.

In addition, how quickly the implied volatility curve converges on a "smile" depends on the way traders learn from the flow of information that the market provides. The role of learning was then investigated by evaluating how different combinations of the two adjustment factors ( $\xi^{1}$ and $\xi^{2}$ ) of traders' volatility expectations (i.e., the one based on the implied volatility and the other on the stock volatility) affect the emergence of the implied volatility smile.

Insert Fig. 4 about here ${ }^{8}$

Considering a moderate level of heterogeneity of traders' beliefs, Fig. 4 shows that the volatility smile is likely to emerge in a market in which traders prefer to update their beliefs

\footnotetext{
${ }^{6}$ The solid line (1) represents an option with time to maturity equal to $360\left(R^{2}=0.96\right.$, curvature $\left.=0.15\right)$, the dotted line (2) an option with time to maturity equal to $180\left(R^{2}=0.98\right.$, curvature $\left.=0.45\right)$, the long dashed line (3) an option with time to maturity equal to $90\left(R^{2}=0.98\right.$, curvature $\left.=0.71\right)$, and the dashed-dotted line (4) an option with time to maturity equal to $30\left(R^{2}=0.98\right.$ curvature $\left.=0.75\right)$. Note that the curvature is evaluated at-the-money. It goes without saying that the higher the value of the curvature, the more the implied volatility function deviates from being flat.

${ }^{7}$ The pattern we derive from our artificial market can also be found in real markets. A trader confessed to us that "it is natural that implied volatility often tends to be higher for out-the-money and in-the-money options compared to at-the-money, because there is an increased risk of potentially very large movements in the underlying [...]; to compensate for this risk we ask for a higher price. Moreover, as maturity is approached, this risk may be even greater, because if something happens, you might not have the time to secure your position" (interview with a trader).

${ }^{8}$ The data presented are taken at the 80th day after the option is launched and represent an average of 100 simulation runs. In the figure, the solid line (1) represents the scenario with $\xi^{1}=0$ and $\xi^{2}=1 \quad\left(R^{2}=0.12\right.$, curvature $=0.05)$, the long dashed line (2) the scenario with $\xi^{1}=0.5$ and $\xi^{2}=0.5\left(R^{2}=0.87\right.$, curvature $\left.=0.45\right)$, the dotted line (3) the scenario with $\xi^{1}=1$ and $\xi^{2}=0\left(R^{2}=0.98\right.$, curvature $\left.=0.76\right)$. As before, note that the curvature is evaluated at the at-the-money point.
} 
according to the implied volatility, instead of relying on the volatility that they may have derived directly from the stock market. Note that curve 1, whereby it can be seen that traders refer to the stock volatility to update their beliefs, is substantially flat, with an R-squared that tends to be close to zero. Conversely, curves 2 and 3 indicate that as soon as traders refer to the implied volatility to update their beliefs, the implied volatility curve takes on the U-shape.

Hence, it is possible to observe that the volatility smile is fueled by traders' tendency to become accustomed over time to the idea that the skew is not only a constant in the face of changing market conditions, but also that it contains useful information that can be incorporated into the decision-making process. ${ }^{9}$ On the one hand, this implies that the more traders who use the implied volatility curve do so to update their beliefs, the faster the implied volatility curve tends to converge to a well-defined U-shaped curve.

\subsection{Adjustment of beliefs over time and traders' wealth}

We have intentionally not invoked the problem of which trading strategy is best suited to guarantee a higher level of wealth to a trader. However, as observed by Rubinstein (1994), due to the uncertainty of the underlying stock volatility, a single free-option price no longer exists. So, it is theoretically possible to gain from the smile by making arbitrages. But in practice there is no way of knowing in advance the true value of the underlying stock volatility. The model proposes a first approach that once developed can be used to derive the beliefs (distribution function) traders have used to price options. If one assumes that these beliefs do not change dramatically over time, a "smart trader" can use these derived beliefs to increase her ability to forecast the "true stock volatility" and accordingly to predict options prices. Eventually, she can even use this information to make arbitrages and to generate higher profits.

A first step in understanding whether rules followed by traders in pricing options contribute to their wealth is to manipulate the form of agent learning. In doing so, we can create a variety of

\footnotetext{
${ }^{9}$ As reported by MacKenzie and Millo (2003: p. 131): "When experienced traders...move to a different pit...say they're trading [options on] telephone [stocks] and now they're going to trade AOL [America Online], the first thing they want to know when they walk into a pit is, 'What's the skew like?' To them that tells them a lot. And it's the most vital information, more than what's the potential earnings of AOL." Apart from this reference and besides the numerical results we obtain from our simulation model, to our knowledge, there has been no discussion in the empirical literature as to how the smile curve depends on the way in which traders update their beliefs over time.
} 
models. Here, we concentrate our analysis on four simple variants. The first three variants focus on situations in which traders use the Black-Scholes model to price options and either update their beliefs with the implied volatility (i.e., $\xi^{1}=1$ and $\xi^{2}=0$ ), or with the historical volatility (i.e., $\xi^{1}=0$ and $\xi^{2}=1$ ), or with a mixture of both (i.e., $\xi^{1}=0.5$ and $\xi^{2}=0.5$ ). In the fourth variant, we consider noise traders who attempt to price options by following a random rule. This last variant provides a nice contrast to the previous three.

A simulation was run by setting for each group of traders $N(K)=1$, the initial trader's wealth at 100 , the current stock price at time 0 equal to 10 , and its dynamics are assumed to follow a Brownian motion, with constant stochastic volatility equal to 0.3 . The strike price ranges between 8 and 13. The coefficient of absolute risk aversion $\gamma$ is kept at 0.8 . Traders' expectations $F_{\Sigma_{i}}$ are modeled as a normal distribution, with its initial mean equal to 0.3 and its standard deviation equal to 0.05 . Lastly, since the demand function is normalized to one, in our model we have, for the sole trader, that $\lambda_{i}(K)$ is either 0 or 1 if the expected option price $\bar{C}_{i, \tau}(K)$ is either lower or higher than the equilibrium price $\widetilde{C}_{0}(K)$.

Results are divided into two categories, according to traders' behavior in updating their beliefs or moneyness. Regarding the latter, a call option is then said to be at-the-money if the ratio between the current price of the underlying assent $S$ and the strike price $K$ is between 0.97 and 1.03; out-of-the-money if the ratio is less than or equal to 0.97 ; and in-the-money if the ratio is greater than or equal to 1.03 (see Bakshi et al., 1997). To appreciate the difference among traders' wealth across the level of moneyness, the maximum wealth traders can earn in each scenario is calculated and used to normalize the mean, the maximum, and the standard deviation of the resulting traders' wealth. Furthermore, to verify the stability of results, we change some of the initial parameters of the simulation (i.e., number of agents, initial traders' wealth, and form of traders' expectations), and we observe that our findings still hold.

From the data, we note that Black-Scholes traders retain a higher level of wealth than noise traders. The former present an average normalized wealth of 0.353 and standard deviation of 0.121 ; and the latter, an average wealth of 0.167 and a standard deviation of 0.154 . This result 
suggests that it is always possible for the "smart" trader to come in and take advantage of the "dumb" (boundedly rational) trader in order to generate higher profits. The analysis was further refined by considering, for Black-Scholes traders, how different rules for updating agents' beliefs affect traders' wealth.

\section{Insert Table 1 about here}

For out-the-money and at-the-money options, Table 1 highlights that those traders who update their beliefs with the implied volatility exhibit a higher increase in their wealth than do those who refer to the historical volatility. This result holds if we refer either to the average or to the maximum wealth. It must be observed that these results are consistent with extant literature. It is well-established that the implied volatility is an upward-biased forecast, but it dominates the historical volatility rate in terms of ex ante forecasting power (e.g., Schmalensee and Trippi, 1978; Fleming, 1998). However, the literature has observed that either the implied volatility has virtually no explanatory power, or its dominance over the historical volatility depends mostly on the type of data, the kind of option, and the averaging period used to calculate the volatility (Canina and Figlewski, 1993).

Accordingly, Table 1 shows that the implied volatility is a better predictor of the future volatility than the historical volatility in all but in in-the-money options. For the latter options, Black-Scholes traders who rely on implied volatility to update their beliefs tend to experience an increase of their wealth that is slightly higher than the increase of wealth gained by traders who refer to the historical volatility. Yet, the difference between the wealth of the two types of traders is statistically insignificant.

This analysis was further extended by considering a financial (derivative) market composed of multiple traders $(N(K)=100)$ with an increasing level of heterogeneity (i.e., from an extreme to a moderate level) and of the two adjustment factors $\xi^{1}$ and $\xi^{2}$ (i.e., from 0 to 1 with steps of 0.25). Results show that as the level of traders' heterogeneity increases, the mean and the maximum level of the wealth of traders who refer to the implied volatility for updating their 
beliefs diminishes. This is explained by the fact that as heterogeneity of traders' beliefs increases, the skew in the implied volatility curve exacerbates and, in turn, the upward bias induced by the traders' use of the implied volatility for pricing options becomes more severe. Nevertheless, this induced bias can be attenuated, and Black-Scholes traders can reach a higher level of wealth if they are able to somehow temper their drive for updating their beliefs with the implied volatility and rely more on the historical volatility. Thus, for in-the-money options traded in financial (derivative) markets composed by heterogeneous traders, a moderate obsession for the implied volatility is one way that allows traders to improve their ability to correctly forecast the future option price and, in turn, to reach a higher level of wealth. Models that incorporate both the implied volatility and the historical data thus show a great deal of promise for pricing options.

\section{Robustness}

The robustness of the simulation results can be seen from different perspectives (e.g., see Axelrod, 1997; Moss and Davidsson, 2001). In this section, we concentrate on three issues.

The first concerns how the presented runs of the model are representative of other possible realizations of the model that might emerge as a result of different runs. Since the simulation results are based on the average of 100 different runs, keeping constant the common set of parameter values, the likelihood of significantly different realizations is very low.

The second concerns the stability of the results. Since our model involves some kind of uncertainty (random inputs are used to generate Black-Scholes traders' beliefs about the underlying stock volatility, noise traders' expectation about options prices, and the values of underlying stock price over time), we performed a bootstrap analysis to verify that the mean (or variance) of a series generated by a simulation experiment is equal to the mean (or variance) of another corresponding series obtained by using different sets of random numbers. Using samples of 2,500 observations extracted randomly from the total population of 5,000 replications for each scenario, we noticed that the difference between the means of the implied volatility across two subsamples of each scenario analyzed is insignificant, in general, in the case considered. The same result is also obtained using subsamples of various sizes. Therefore, our results are stable, 
with moments (mean and variance) holding across diverse replications of the simulation, and, in turn, any given replication of the simulation is likely to be fairly representative of the population of the potential simulation output. Lastly, despite the arbitrariness in the particular selection of parameters, we find our initial choices do not alter the findings when we vary the coefficient of risk aversion, the type of distribution function of traders' beliefs, the number of traders, and the time at which a buyer sells her holdings. ${ }^{10}$

The third issue concerns how the model is able to capture the reality of financial (derivative) markets and, specifically, how the results from the simulated experiments match the results from real financial markets. This is a tedious point, involving some complex analyses that can be carried out in different ways (e.g., see Naylor and Finger, 1967, with the attached critiques; Van Horn, 1971; and more recently, Nelson, 2004). Thus, we compare the simulation model outputs (i.e., option prices and the implied volatility curve) with the empirical data, assuming that inputs of the model are representative of inputs used by traders to price options in financial markets.

We consider the simplest case of a financial (derivative) market composed of two types of Black-Scholes traders. In other words, the set of $N$ Black-Scholes traders is divided into two disjoint subsets A and B, with $N(K)=N_{A}(K)+N_{B}(K)$ and for each $i \in\{1, \ldots, N\}, \widehat{E}_{i, \tau}$ is equal either to $\widehat{E}_{A, \tau}$ or to $\widehat{E}_{B, \tau}$ depending on whether $i \in A$ or $i \in B$. Similarly, we have that either $\delta_{i, \tau}(K)=\delta_{A, \tau}(K)$ or $\delta_{i, \tau}(K)=\delta_{B, \tau}(K)$. We also assume that for trader in A, $\Sigma$ has a distribution $F_{\Sigma_{A}}$, while for traders in $\mathrm{B}, \Sigma$ has a distribution $F_{\Sigma_{B}}$. Both distributions are modeled as a generalized inverse Gaussian distribution (GIG) with parameters $a>0, b>0$ and $q \in R$. As observed in the pioneering paper of Eberlein and Keller (1995), this assumption on the distribution of traders' beliefs implies that Black-Scholes traders suppose a generalized hyperbolic distribution (which is a mixture of normals) for daily returns instead of a normal distribution (as in the standard Black-Scholes price). Note that by using such a hyperbolic distribution, a modified version of Black-Scholes can be obtained to price options. Finally, for

\footnotetext{
${ }^{10}$ Data and tests results are here omitted and are available on the $J E B O$ website.
} 
the sake of simplicity, we propose that traders' beliefs do not change over time $\left(\xi^{1}=\xi^{2}=0\right)$, and that all traders share the same coefficient of absolute risk aversion $\left(\gamma_{A}=\gamma_{B}=\gamma\right)$.

This version of our model was calibrated to S\&P 500 call option data, which have been the focus of many existing investigations (e.g., Rubinstein, 1994). The sample period extends from June 1, 1996, through May 31, 2000. As proposed in Bakshi et al. (1997), options with less than six days till expiration and quotes that do not satisfy the arbitrage restriction are excluded from the sample. The closing bid-ask quotas for S\&P 500 call options are collected from Compustat. Following Jackwerth and Rubinstein (1996), nominal interest rates are recovered from "put-call parity." Moreover, the annualized payout return $d$ at a given date for a given option with yearsto-expiration $y$ is calculated as $d=[1+(D / S)]^{y}$, where $D$ is the simple sum of the actual S\&P 500 daily dividend amounts associated with ex-dividend dates between the given date and the given expiration date, and $S$ the S\&P 500 spot index level. In Table 2, we report the average bid-ask mid-point price, the average implied volatility which is shown in parentheses, and the total number of observations (in braces) for each moneyness-maturity category.

Insert Table 2 about here

In order to reduce the number of parameters to be estimated, we directly derive the constant absolute risk aversion from risk-neutral and physical-state probabilities. Following Kliger and Levy (2003), risk-neutral probabilities $P_{v, t}$ and physical-state probabilities $P_{v, t}^{a}$ are estimated over the possible state of nature $V$, with $v=1, \ldots, V$. Coefficients of absolute risk aversion are then evaluated according to the following expressions:

$$
\gamma=\left(\delta P_{v, t}^{a} / \delta S_{t+\tau, v}\right) / P_{v, t}^{a}-\left(\delta P_{v, t} / \delta S_{t+\tau, v}\right) / P_{v, t},
$$

with $S_{t+\tau, v}$ the $v^{\text {th }}$ state index level at time $t+\tau$ (see also Hansen and Singleton, 1982). Using prices sampled on a monthly basis, we obtain an average coefficient of absolute risk aversion $\gamma$ of 28.28 with a standard deviation of 86.88 . We also have that $\gamma \equiv\{114.13,10.54,86.88\}$ for values of $x \equiv\{-0.2,0,0.2\}$. 
From our data set, we extract $M$ option prices on the same index, taken from the same day, for any $M$ greater than or equal to 1 , plus the number of parameters to be estimated. For each $m=1, \ldots, M$, let $\widetilde{C}_{m}\left(t, T_{m}, K_{m}\right)$ be the observed price and $\widetilde{C}_{m}^{\Phi}\left(t, T_{m}, K_{m}\right)$ be the estimated price as determined by our model, with $S$ and $r$ taken directly from the financial market. Therefore, the difference between $\widetilde{C}_{m}\left(t, T_{m}, K_{m}\right)$ and $\widetilde{C}_{m}^{\Phi}\left(t, T_{m}, K_{m}\right)$ is assumed to be a function of the value taken by $\Phi=\left\{a_{A}, b_{A}, q_{A}, a_{B}, b_{B}, q_{B}\right\}$. Thus, for each $m$ we define

$$
g_{m}[\Phi]=\widetilde{C}_{m}\left(t, T_{m}, K_{m}\right)-\widetilde{C}_{m}^{\Phi}\left(t, T_{m}, K_{m}\right)
$$

and find the parameter vector $\Phi$ to solve

$$
\operatorname{SSE}(t) \equiv \inf _{\Phi} \sum_{m=1}^{M}\left|g_{m}[\Phi]\right|^{2}
$$

Implementing the above procedure, we use all call options available at each given day as inputs to estimate that day's spot volatility and relevant parameters. The group in Table 3 reports the average and the standard deviation for each parameter implied by all options in the sample, by all short-, medium-, or long-term options. The daily average sum of squared errors (SSE) and the out-of-sample percentage pricing errors are also reported. Note that percentage errors are obtained using the parameters implied by the previous day's options of a given maturity to price the current day's options of the same maturity.

\section{Insert Table 3 about here}

Given the characteristic of the GIG function, confronting the average parameter values implied by each day's short-term calls with their counterparts implied by all options of each given day, the result is that traders believe the underlying stock volatility increases slightly, as the time to maturity is approached. The average of the stock volatility for a given option, as expected by all traders, is equal to 0.1510 , while for short-term options it is equal to 0.1523 , for medium-term options it is equal to 0.1520 , and for long-term options it is equal to 0.1449 . We also observe that the highest level of heterogeneity of traders' beliefs is recorded for short-term options. As reported in Table 3, the absolute difference between the average value of the 
underlying stock volatility as expected by traders A and traders B is equal to 0.003 for short-term options, while it is equal to 0.0005 for medium-term options, and to 0.0004 for long-term options. And finally, the in-sample fit (SSE) ranges between 18 and 37. These values are fairly acceptable, considering that Bakshi et al. (1997) reported for the Black-Scholes model an SSE of 69.60 for all options and 28.09 for short-term options. We also find that the out-of-sample percentage pricing errors are reasonably acceptable, considering again that Bakshi et al. (1997) reported - for the Black-Scholes model — errors (maturity-based) extending between $1.18 \%$ and $-82.99 \%$, with an average value of $-7.93 \%$ for short-term options, $-7.57 \%$ for medium-term options, and $-4.52 \%$ for long-term options. In addition, for each given call option of date $t$, we compare the implied volatility patterns derived from financial markets with the implied volatility patterns derived from the simulated data across both moneyness and maturity. After repeating these steps for all options in the sample, we then obtain for each moneyness-maturity category an average implied volatility value. As it turns out, not only does the minimum of the simulated curve approach that of the empirical curve, but its shape also tends to resemble that of the empirical data during the option life cycle.

\section{Discussion and conclusions}

Let us now draw together the threads of our results. The problem posed at the outset was how to explain the implied volatility smile. We accomplished this task by proposing an extended computational model of option pricing using agent-based simulation techniques. Our model pays particular attention to issues of heterogeneity of traders' beliefs, learning, and institutionalized norms, and inspects their implications for the emergence of the volatility smile. While most available accounts consider the option price decision as a mathematical problem, we underscore the fact that the story behind the problem is indeed much richer. In the proposed model, agents do not simply decide, arbitrarily, whether to buy or sell a given option at a given price; in an uncertain environment, they are guided by institutionalized norms, relying on their subjective beliefs and learning about the underlying stock volatility from the incoming flow of information the market provides over time. As North (1990) has noted: "Institutions are the humanly devised 
constraints that shape human interaction. They reduce uncertainty by providing a structure to political, social, and economic exchange" (p. 182). In other words, institutions matter.

The results of our model suggest the following. We notice that the "smile" in the implied volatility curve is likely to emerge in an environment in which traders rely on their subjective beliefs to resolve their uncertainty about the underlying stock volatility and use the widely accepted Black-Scholes formula to price options. The smile effect emerges clearly from simulation data in the Black-Scholes scenario but not in the noise scenario. In the latter, the resulting implied volatility function is substantially different from that represented by a welldefined U-shape. Moreover, heterogeneity of traders' beliefs and the way traders update their expectations have nontrivial effects both on equilibrium prices and on the emergence of the implied volatility smile.

But this is not the only contribution to which we aspire. We offer a novel approach to modeling the processes of option pricing by considering a type of selective behavior and by relating it to certain concepts developed within the behavioral theory of human decision making. Thus, our paper also contributes to our understanding of these complex phenomena without rendering their subsequent analysis more difficult, and it can be expected to have important implications for asset pricing in general. Regarding the latter point, consider a financial market composed of $N$ traders divided into $\Omega$ disjoint subsets, with each trader having a set of beliefs represented by a family of distribution functions that depends on $H$ parameters. Given the empirical implied volatility function, the problem posed at the outset is how to find a consistent, quick, and robust way to estimate both the parameters of the distribution functions, which express traders' beliefs, and the cardinality of $\Omega$ from the history of bid and ask prices available on the market.

Although we have focused our discussion on European call options, the basic ideas embodied in the model are much broader and can be quite useful to other kinds of options. Specifically, our model applies to and, accordingly, our explanation of the implied volatility smile extends to European put options, via the 'put-call parity', and to American call options, which are equal, in only a trivial manner, to European calls (see Ncube and Satchell, 1997; Björk, 2004). A similar 
statement is not possible for American puts because there is no analytical formula to estimate their price, which, in turn, is required to calculate the implied volatility. However, our agentbased simulation model can be extended by considering a financial (derivative) market where traders deal with American puts, use simple rules of thumb, and follow their subjective expectations to resolve the uncertainty around the underlying stock volatility and the time at which it is convenient to exercise the right to sell the asset. This topic offers potential avenues for future research.

\section{Appendix A. A mathematical explanation of the implied volatility smile}

If we assume that $t=0$, the current stock price $S_{0}=s$, the free-risk interest rate $r$ and the time-until-option expiration $T$ are fixed, and call options are priced according to the BlackScholes model, we then have: ${ }^{11}$

$$
\varphi(v, K)=C^{B . S .}(s, r, T, K, v)
$$

The problem in using the latter formula is that the value of $v$ is unknown to the trader. Nevertheless, it is well-established that:

$$
\begin{aligned}
\frac{\partial}{\partial v} \varphi(v, K) & =s \sqrt{T} \phi^{\prime}\left(\frac{\log (s / K)+\left(r+v^{2} / 2\right) T}{v \sqrt{T}}\right) \\
& =s \sqrt{T} \frac{1}{\sqrt{2 \pi}} \exp \left\{-\frac{1}{2}\left(\frac{\log (s / K)+\left(r+v^{2} / 2\right) T}{v \sqrt{T}}\right)^{2}\right\}>0
\end{aligned}
$$

and since expression (7) - which measures the sensitivity of option price to its implied volatility (i.e., vega) - is positive for each value of $\mathrm{K}$, the function

$$
h_{K}: v \rightarrow h_{K}(v):=\varphi(v, K)
$$

is strictly increasing and therefore invertible. Thus, a first approach to understanding the value of $\sigma$ is to observe the market price of a call option $\widetilde{C}(K)$ with strike price $K$. By inverting the option pricing formula, the trader can calculate the annual volatility implied by the market price. Nevertheless, the equilibrium market price does not follow the Black-Scholes model. As

\footnotetext{
${ }^{11}$ For the sake of simplicity we set $t=0$, and therefore we drop from all formulas the dependence on $t$ (e.g., $\hat{\sigma}_{t}$ will be denoted by $\hat{\sigma}$ ). On the other hand, we use a generic time to maturity $T$.
} 
observed, the implied stock volatility varies as $K$ varies. As a consequence of that variance, we have that the implied volatility is a quadratic function of $K$ :

$$
\hat{\sigma}(K)=h_{K}^{-1}(\widetilde{C}(K))
$$

The following proposition illustrates the characteristics of the function $K \rightarrow \hat{\sigma}(K)$ and proposes a theoretical explanation for the emergence of the volatility smile effect.

Proposition 1. If we assume that traders are homogeneous (i.e., $F_{\Sigma_{1}}=F_{\Sigma_{2}}=, \ldots,=F_{\Sigma_{N}}$ ), their beliefs do not change across strike prices (i.e., $\left.\delta_{., \tau}\left(K_{1}\right)=\delta_{., \tau}\left(K_{2}\right)=, \ldots, \delta_{., \tau}\left(K_{j}\right)\right), \widetilde{C}(K)$ is evaluated as in (3), and $\hat{\sigma}(K)$ is evaluated as in (9), then we have:

$$
\hat{\sigma}\left(K_{1}\right) \leq \hat{\sigma}\left(K_{2}\right) \Leftrightarrow\left(\log \left(s / K_{1}\right)+r T\right)^{2} \leq\left(\log \left(s / K_{2}\right)+r T\right)^{2}
$$

This is to say that $\hat{\sigma}$ is an increasing function of $(\log (s / K)+r T)^{2}$.

Proof. First of all, from Eq. (3) the equilibrium market price of the option is

$$
\widetilde{C}(K)=\frac{1}{N}\left[\sum_{i=1}^{N} \bar{C}_{i, \tau}(K)-2 \cdot e^{-r \tau} \sum_{i=1}^{N} \gamma_{i} \delta_{i, \tau}(K)\right]
$$

The above expression can be written as:

$$
\widetilde{C}(K)=a+b \cdot \widehat{C}_{T o t}(K)
$$

where

$$
\widehat{C}_{T o t}(K)=\frac{1}{N} \sum_{i=1}^{N} \int_{0}^{\infty} \varphi_{i}(v, K) F_{i, \Sigma}\{d v\}=\int_{0}^{\infty} \varphi(v, K) F_{\Sigma}\{d v\}
$$

Considering that $\widetilde{C}(K)$ is a linear transformation of $\widehat{C}_{T o t}(K)$ and since $b$ is positive, it is possible to turn our attention to $\widehat{C}_{\text {Tot }}(K)$. In doing so, we write down the implied stock volatility as:

$$
\hat{\sigma}(K)=h_{K}^{-1}\left(\widehat{C}_{T o t}(K)\right)=h_{K}^{-1}\left(E\left[h_{K}(\Sigma)\right]\right)
$$

The thesis is immediately achieved by using the general result of the following proposition.

Proposition 2. Set

$$
\hat{\sigma}(K)=h_{K}^{-1}\left(E\left[h_{K}(\Sigma)\right]\right)=h_{K}^{-1}\left(\int_{0}^{\infty} \varphi(v, K) F_{\Sigma}\{d v\}\right)
$$


with $\varphi$ as defined above, and $F_{\Sigma}$ a generic nondegenerate distribution function, then we have: ${ }^{12}$

$$
\hat{\sigma}\left(K_{1}\right) \leq \hat{\sigma}\left(K_{2}\right) \Leftrightarrow\left(\log \left(s / K_{1}\right)+r T\right)^{2} \leq\left(\log \left(s / K_{2}\right)+r T\right)^{2}
$$

Proof. First, note that the thesis is equivalent to

$$
\hat{\sigma}\left(K_{1}\right) \leq \hat{\sigma}\left(K_{2}\right) \Leftrightarrow l^{2}\left(K_{1}\right) \leq l^{2}\left(K_{2}\right)
$$

where $l(K)=\log \left(s e^{r t} / K\right)$ is the so-called log-moneyness.

According to the theories of Nagumo (1930), Kolmogoroff (1930), and de Finetti (1931), given a stochastic variable $X$, and a strictly increasing and continuous function $h$ :

$$
M_{h}(X):=h^{-1}(E[h(X)])
$$

is an associative mean. Then the implied volatility $\hat{\sigma}(K)$ is the associative mean of $\Sigma$ with $h=h_{K}$. Furthermore, as observed in de Finetti (1931), given a random variable $X$ whose distribution function is defined in $D:=\operatorname{supp}(X)$, and two invertible and strictly regular functions $h$ and $g$ in $D$, we have:

$$
M_{h}(X):=h^{-1}(E[h(X)])<M_{g}(X):=g^{-1}(E[g(X)])
$$

if and only if

$$
\frac{h^{\prime \prime}(x)}{h^{\prime}(x)}<\frac{g^{\prime \prime}(x)}{g^{\prime}(x)}
$$

for all $x$ that belong to $D$. The above property is equivalent to the convexity of the function $g\left(h^{-1}().\right)$. The convexity is strict when the inequality in (11) is strict. In this case, then, the inequality in (12) is also strict, except in the degenerate case. To obtain the result of the proposition, it is enough to show that

$$
\frac{h_{K_{1}}^{\prime \prime}(v)}{h_{K_{1}}^{\prime}(v)}<\frac{h_{K_{2}}^{\prime \prime}(v)}{h_{K_{2}}^{\prime}(v)}, \forall v>0
$$

if and only if $l^{2}\left(K_{1}\right)<l^{2}\left(K_{2}\right)$. The last statement is easily seen from the equality

$$
\frac{h_{K}^{\prime \prime}(v)}{h_{K}^{\prime}(v)}=\frac{l^{2}(K)-\left(v^{2} T / 2\right)^{2}}{v^{2} T}
$$

\footnotetext{
${ }^{12}$ A generic distribution function $F^{\theta}$ is degenerate if there exists at least one value such that $P^{\theta}(X=r)=1$ for all $\theta$. If the function is not degenerate, it is called nondegenerate.
} 
which is a straightforward consequence of the fact that:

$$
h_{K}^{\prime}(v)=s \sqrt{T} \frac{1}{\sqrt{2 \pi}} \exp \left\{-\frac{1}{2}\left(\frac{l(K)}{v \sqrt{T}}+\frac{v \sqrt{T}}{2}\right)^{2}\right\}
$$

coincides with (7) (i.e., the vega).

Proposition 1 implies that there exists an increasing function $f=f_{F_{\Sigma}}$ such that $\hat{\sigma}(K)=f_{F_{\Sigma}}\left(l^{2}(K)\right)$. This function reaches its minimum in $K=K_{a t}:=s e^{r T}$ (at-the-money), and if $\Sigma$ is a nondegenerate random variable, the function $f$ is also strictly increasing. This fact can already be considered as a simple theoretical explanation of the emergence of the volatility smile effect. Under some further mild conditions, one can obtain a new proof of the announced local convexity property for the implied volatility, as it is explained by the following remark.

Remark 1. Let $f=f_{F_{\Sigma}}$, the increasing function of the proposition 1 , be a $C^{2}([0, \infty])$ function with $f^{\prime}(0)>0$. Then the function $\hat{\sigma}(K)$ is convex in a neighborhood around the future price $K_{a t}$

Proof. It is sufficient to show that in the neighborhood of $s e^{r T}$, the second derivative of the function $g(x):=f\left(\ell^{2}(K)\right)$ is positive. Posing $\ell_{2}(x):=\ell^{2}(K)$, we have

$$
\begin{aligned}
& g^{\prime}(x)=f^{\prime}\left(\ell_{2}(x)\right) \ell_{2}^{\prime}(x) \\
& g^{\prime \prime}(x)=f^{\prime \prime}\left(\ell_{2}(x)\right)\left(\ell_{2}^{\prime}(x)\right)^{2}+f^{\prime}\left(\ell_{2}(x)\right) \ell_{2}^{\prime \prime}(x)
\end{aligned}
$$

where

$$
\begin{aligned}
\ell_{2}^{\prime}(x)= & \frac{d}{d x}\left(\log \left(s e^{r T}\right)-\log (x)\right)^{2}=2\left(\log \left(s e^{r T}\right)-\log (x)\right) \cdot\left(-\frac{1}{x}\right) \\
\ell_{2}^{\prime \prime}(x)= & \frac{d^{2}}{d x^{2}}\left(\log \left(s e^{r T}\right)-\log (x)\right)^{2}=2\left(\frac{1}{x}\right)^{2}+2\left(\log \left(s e^{r T}\right)-\log (x)\right) \cdot\left(\frac{1}{x^{2}}\right) \\
& =\left(\frac{2}{x^{2}}\right)\left(1+\log \left(s e^{r T}\right)-\log (x)\right) .
\end{aligned}
$$

Since $\ell_{2}(x)$ and $\ell_{2}^{\prime}(x)$ tend to 0 as $x$ approaches $s e^{r T}$, and $\ell_{2}^{\prime \prime}(x)$ tends to $\frac{2}{s^{2} e^{2 r T}}>0$ as $x$ goes to $s e^{r T}$, we have that: 


$$
\lim _{x \rightarrow s e^{r T}} g^{\prime \prime}(x)=f^{\prime \prime}(0) \cdot 0+f^{\prime}(0) \cdot \frac{2}{s^{2} e^{2 r T}}=f^{\prime}(0) \cdot \frac{2}{s^{2} e^{2 r T}}>0,
$$

and this concludes the proof.

\section{Acknowledgment:}

Giovanna Nappo and Fabio Massimo Marchetti provided invaluable contributions to the development of the paper and, specifically, to the mathematical explanation of the emergence of the implied volatility smile. I thank two anonymous referees for very useful comments and suggestions. I'm also grateful to seminar participants at the Academy of Management Journal 2007 conference (Philadelphia). Support from Sapienza, University of Rome is gratefully acknowledged.

\section{References}

Arthur, B., 1994. Inductive reasoning and bounded rationality. American Economic Review 84, 406-411.

Arthur, B., Holland, J. H., LeBaron, B., Palmer, R., Taylor, P., 1997. Asset pricing under endogenous expectations in an artificial stock market. In: Arthur, B., Durlauf, S. N., Lane D. A. (Eds). The Economy as an Evolving Complex System, Vol. II. Reading, MA: Addison-Wesley, 15-44.

Axelrod, R. M., 1997. The Complexity of Cooperation: Agent-Based Models of Competition and Collaboration. Princeton, NJ: Princeton University Press.

Bakshi, G., Cao, C., Chen, Z., 1997. Empirical performance of alternative option pricing models. Journal of Finance 52, 2003-2049.

Barlevy, G., Veronesi, P., 2000. Information acquisition in financial markets. Review of Economic Studies 67, 79-90.

Björk, T., 2004. Arbitrage Theory in Continuous Time. Oxford: Oxford University Press.

Black, F., 1975. Fact and fantasy in the use of options. Financial Analysts Journal 31, 36-72.

Black, F., Scholes, M., 1973. The pricing of options and corporate liabilities. Journal of Political Economy 81, 637-654. 
Brandt, M. W., Jones, C. S., 2006. Volatility forecasting with range-based EGARCH models. Journal of Business \& Economic Statistics 24, 470-486.

Brigo, D., Mercurio, F., 2002. Lognormal-mixture dynamics and calibration to market volatility smiles. International Journal of Theoretical and Applied Finance 5, 427-446.

Broadie, M., Detemple, J. B., 2004. Option pricing: Valuation models and applications. Management Science 50, 1145-1177.

Callon, M., 1998. The Laws of the Markets. Oxford: Blackwell.

Canina, L., Figlewski, S., 1993. The informational content of implied volatility. Review of Financial Studies 6, 659-681.

Cohen, K. J., Cyert, R., 1965. Simulation of organizational behavior. In March, J. (Ed.). Handbook of Organizations. Chicago: Rand McNally \& Company, 305-334.

Constantinides, G. M., 1997. Transaction costs and the pricing of financial assets. Multinational Finance Journal 1, 93-99.

Cont, R., da Fonseca, J., 2002. The dynamics of implied volatility surfaces. Quantitative Finance 2, 45-60.

Conway, R. W., Johnson, B. M., Maxwell, W. L., 1959. Some problems of digital systems simulation. Management Science 6, 92-110.

Cyert, R. M., March, J., 1963. A Behavioral Theory of the Firm. Englewood Cliffs, NJ: PrenticeHall.

Dawid, H., Fagiolo, G., 2008. Agent-based models for economic policy design: Introduction to the special issue. Journal of Economic Behavior \& Organization 67, 351-354.

De Finetti, B., 1931. Sul concetto di media. Giornale dell'Istituto Italiano degli Attuari 2, 369396.

De Long, J. B., Shleifer, A., Summers, L. H., Waldmann, R. J., 1990. Noise trader risk in financial markets. Journal of Political Economy 98, 703-738.

Derman, E., Kani, I., 1994. Riding on a smile. Risk 7, 32-39.

Detemple, J. B., Osakwe, C., 2000. The valuation of volatility options. European Finance Review 4, 21-50. 
Duffie, D., Pan, J., Singleton, K., 2000. Transform analysis and option pricing for affine jumpdiffusions. Econometrica 68, 1343-1376.

Eberlein, E., Keller, U., 1995. Hyperbolic distributions in finance. Bernoulli 1, 281-299.

Ehrentreich, N., 2006. Technical trading in the Santa Fe Institute Artificial Stock Market revisited. Journal of Economic Behavior \& Organization 61, 599-616.

Figlewski, S., 1989. Options arbitrage in imperfect markets. Journal of Finance 34, 1289-1311.

Fleming, J., 1998. The quality of market volatility forecasts implied by S\&P 100 index option prices. Journal of Empirical Finance 5, 317-345.

Fouque, J. P., Papanicolaou, G., Sircar, R., 2001. From the implied volatility skew to a robust correction to Black-Scholes American option prices. International Journal of Theoretical and Applied Finance 4, 651-675.

Freund, R., 1956. The introduction of risk into a programming model. Econometrica 24, 253 263.

Galai, D., 1983. A survey of empirical tests of option pricing models. In: Brenner, M. (Ed.). Option Pricing: Theory and Applications. Lexington, MA: Lexington Books, 45-81.

Grossman, S. J., Stiglitz, J. E., 1980. On the impossibility of informationally efficient markets. American Economic Review 70, 393-408.

Hafner, R., Wallmeier, M., 2001. The dynamics of DAX implied volatilities. International Quarterly Journal of Finance 1, 1-27.

Hansen, L. P., Singleton, K., 1982. Generalized instrumental variables estimation of non-linear rational expectations models. Econometrica 50, 1269-1286.

Holland, J. H., Miller, J. H., 1991. Artificial adaptive agents in economic theory. American Economic Review 81, 365-370.

Hull, J., White, A., 1987. The pricing of options on assets with stochastic volatilities. Journal of Finance 42, 281-300.

Hull, J., 1993. Options, Futures, and other Derivative Securities. Englewood Cliffs, NJ: Prentice Hall. 
Jackwerth, J. C., Rubinstein, M., 1996. Recovering probability distributions from option prices. Journal of Finance 51, 1611-1631.

Jean-Marie, A., Tidball, M., 2006. Adapting behaviors through a learning process. Journal of Economic Behavior \& Organization 60, 399-422.

Keynes, J. M., 1936. The General Theory of Unemployment, Interest, and Money. New York: Harcourt, Brace \& World.

Kleijnen, J. P., 1988. Analyzing simulation experiments with common random numbers. Management Science 34, 65-74.

Kliger, D., Levy, O., 2003. Mood-induced variation in risk preferences. Journal of Economic Behavior \& Organization 52, 573-584.

Kolmogoroff, A., 1930. Sur la notion de moyenne. Revue des Lincei 9, 30-45.

Kou, S. G., 2002. A jump-diffusion model for option pricing. Management Science 48, 10861101.

LeBaron, B., Arthur, W. B., Palmer, R., 1999. Time series properties of an artificial stock market. Journal of Economic Dynamics and Control 23, 1487-1516.

Li, H., Rosser, J. B., 2001. Emergent volatility in asset markets with heterogeneous agents. Discrete Dynamics in Nature and Society 6, 171-180.

Longstaff, F. A., 1995. Option pricing and the martingale restriction. Review of Financial Studies 8, 1091-1124.

Macbeth, J., Merville, L. J., 1979. An empirical examination of the Black-Scholes call option pricing model. Journal of Finance 34, 1173-1186.

MacKenzie, D., Millo, Y., 2003. Constructing a market, performing theory: The historical sociology of a financial derivatives exchange. American Journal of Sociology 109, 107145.

Merton, R., 1976. Option pricing when underlying stock returns are discontinuous. Journal of Financial Economics 3, 125-144.

Moss, S., Davidsson, P., 2001. Multi-Agent-Based Simulation. Lecture Notes in Artificial Intelligence. Verlag: Springer. 
Ncube, M., Satchell, S., 1997. The statistical properties of the Black-Scholes option price. Mathematical Finance 7, 287-305.

Nagumo, M., 1930. Notes on the concept of average. Japanese Journal of Mathematics 6, 71-75.

Natenberg, S., 1994. Option Volatility and Pricing. Chicago: Probus Publishing.

Naylor, T. H., Finger, J. M., 1967. Verification of computer simulation models. Management Science 14, B92-B101.

Nelson, B. L., 2004. Stochastic simulation research in Management Science. Management Science 50, 855-868.

North, D. C., 1990. Institutions and a transaction-cost theory of exchange. In: Alt, J. E., Shepsle, K. A. (Eds.). Perspectives on Positive Political Economy. New York: Cambridge University Press, 182-194.

Palmer, R. G., Arthur, B., Holland, J. H., LeBaron, B., Taylor, P., 1994. Artificial economic life: A simple model of a stockmarket. Physica D 75, 264-274.

Renault, E., Touzi, N., 1996. Option hedging and implied volatilities in a stochastic volatility model. Mathematical Finance 9, 279-302.

Roth, A., 2002. The economist as engineer: Game theory, experimentation, and computation as tools for design economics. Econometrica 70, 1341-1378.

Routledge, B. R., 1999. Adaptive learning in financial markets. Review of Financial Studies 12, 1165-1202.

Rubinstein, M., 1985. Nonparametric tests of alternative option pricing models using all reported trades and quotes on the 30 most active CBOE option classes from August 23, 1976, through August 31, 1978. Journal of Finance 40, 455-480.

Rubinstein, M., 1994. Implied binomial trees. Journal of Finance 49, 771-818.

Schelling, T. C., 1960. The Strategy of Conflict. Cambridge, MA: Harvard University Press.

Schmalensee, R., Trippi, R., 1978. Common stock volatility expectations implied by option premia. Journal of Finance 33, 129-147.

Simon, H. A., 1957. Application of servomechanism theory to production control. In: Simon, H. A. (Ed). Models of Man. New York: John Wiley \& Sons, 219-240. 
Sircar, R., Papanicolaou, G., 1999. Stochastic volatility, smile and asymptotics. Applied Mathematical Finance 6, 107-145.

Tesfatsion, L. S., Judd, K., (Eds.) 2006. Handbook of Computational Economics. Agent-Based Computational Economic, Vol. II. Amsterdam: North Holland.

Van Horn, R. L., 1971. Validation of a simulation results. Management Science 17, 247-258.

Ziegler, A., 2002. State-price densities under heterogeneous beliefs, the smile effect, and implied risk aversion. European Economic Review 46, 1539-1557. 


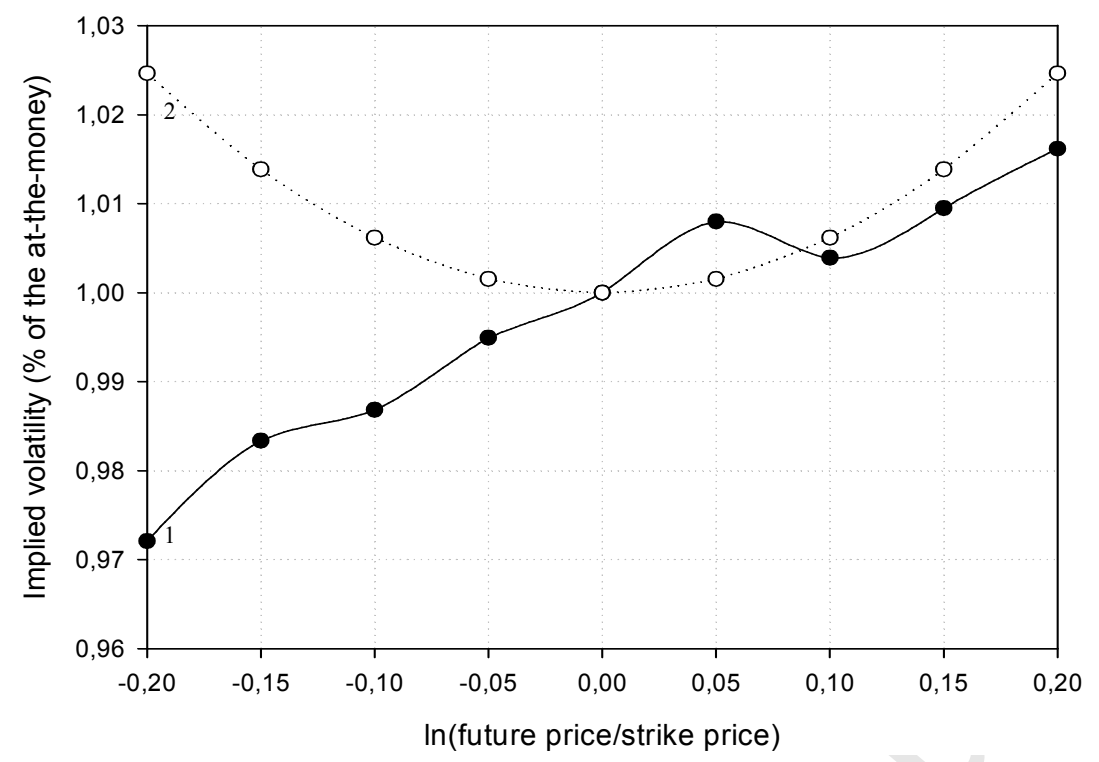

Fig. 1. The implicit volatility as function of the log-moneyness in a typical simulation run 


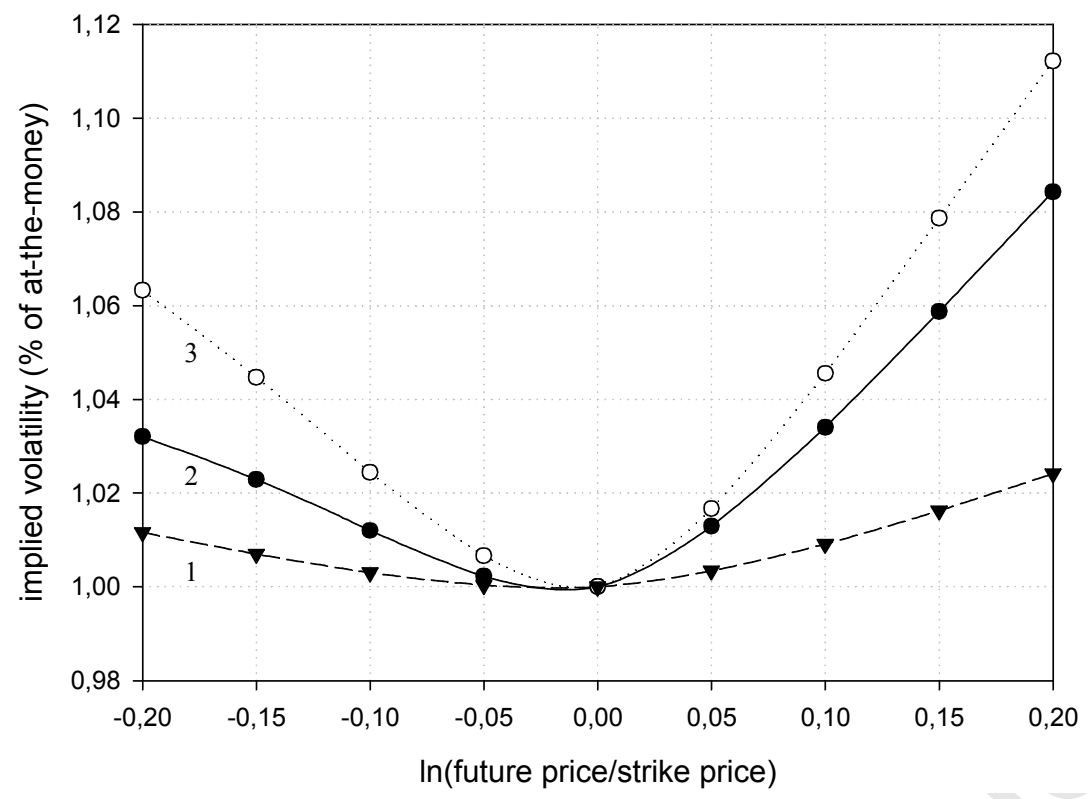

Fig. 2. Impact of traders' heterogeneity on the implied volatility function for the Black-Scholes scenario 


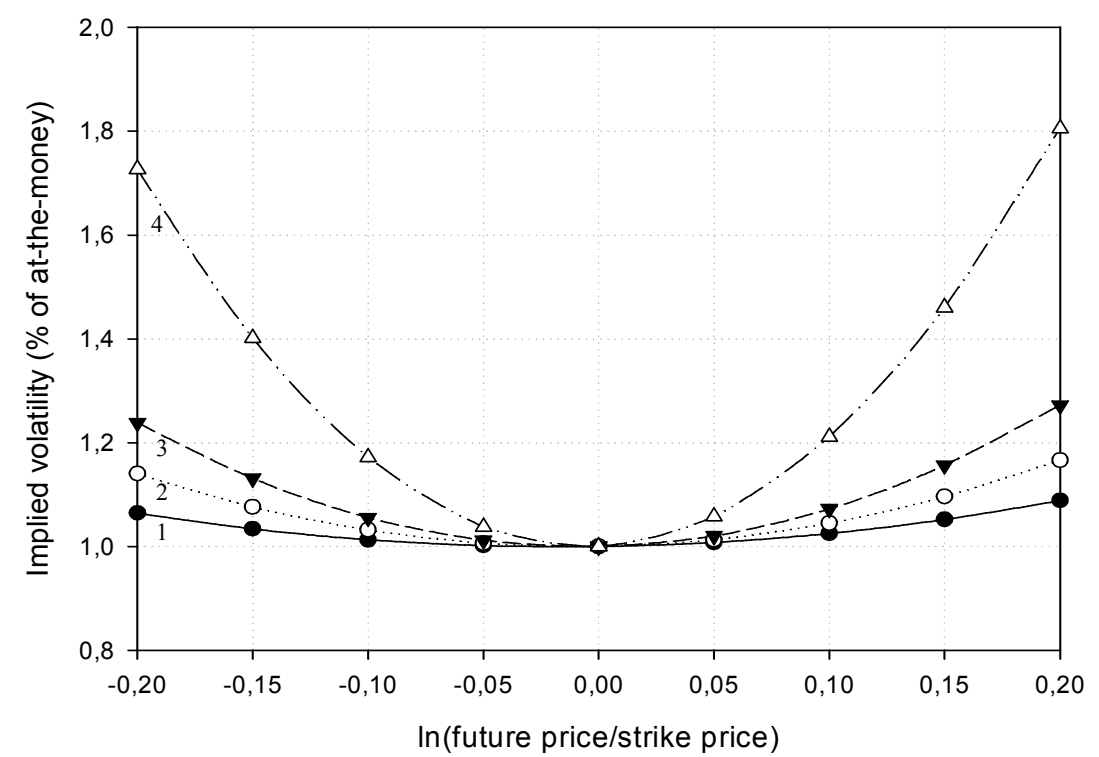

Fig. 3. The evolution of implied volatility smile over time for the Black-Scholes scenario with moderate levels of heterogeneity $\left(\xi^{1}=\xi^{2}=0.01\right)$ 


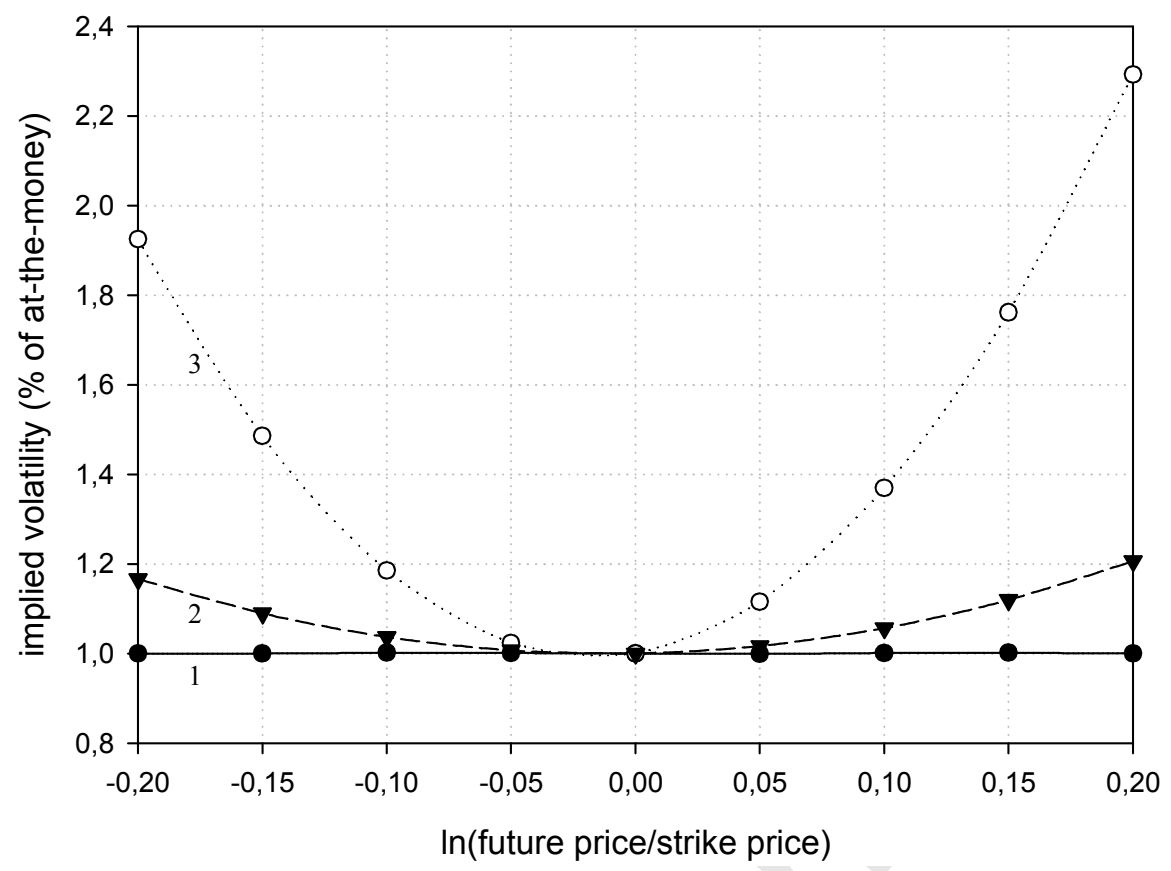

Fig. 4. Combined effect of beliefs adjustment based on implied volatility $\xi^{1}$ and on stock volatility $\xi^{2}$ on the volatility smile for the Black-Scholes scenario with moderate levels of heterogeneity 


\begin{tabular}{|llccccc|}
\hline & & \multicolumn{2}{c}{ Mean traders wealth } & & \multicolumn{2}{c|}{ Max traders wealth } \\
\cline { 3 - 3 } \cline { 6 - 7 } Moneyness & & $\begin{array}{c}\text { Historical } \\
\text { volatility }\end{array}$ & $\begin{array}{c}\text { Implied } \\
\text { volatility }\end{array}$ & & $\begin{array}{c}\text { Historical } \\
\text { volatility }\end{array}$ & $\begin{array}{c}\text { Implied } \\
\text { volatility }\end{array}$ \\
\hline out-of-the-money & Mean & 0.297 & 0.448 & & 0.473 & 0.843 \\
$(\mathrm{~S} / \mathrm{K}<0.97)$ & S.D & 0.042 & 0.110 & & 0.081 & 0.216 \\
& $t$-Stat. & & $0.041^{*}$ & & & $0.034^{*}$ \\
\hline at-of-the-money & Mean & 0.326 & 0.443 & & 0.614 & 0.903 \\
$(0.97<$ S/K $<1.03)$ & S.D & 0.091 & 0.156 & & 0.150 & 0.260 \\
& $t$-Stat. & & $0.021^{*}$ & & & $0.018^{*}$ \\
\hline in-the-money & Mean & 0.309 & 0.313 & & 0.605 & 0.623 \\
$(\mathrm{~S} / \mathrm{K}>1.03)$ & S.D & 0.169 & 0.172 & & 0.184 & 0.189 \\
& $t$-Stat. & & 0.001 & & & 0.001 \\
\hline
\end{tabular}

* Difference is significant at the $1 \%$ level.

Mean and max wealth are calculated over the option life cycle for each type of trader and normalized over the maximum wealth a trader can earn in each scenario. The significance of the difference in mean and maximum wealth values between different kinds of traders was tested using a two-sided paired t-test.

Tab. 1 - Comparison of traders' wealth for agents who use either the historical volatility or the implied volatility to update their beliefs 


\begin{tabular}{lcccc}
\hline & \multicolumn{3}{c}{ Days-to-expiration } & \\
\cline { 2 - 4 } Moneyness (S/K) & $<60$ & $60-180$ & $>180$ & Subtotal \\
\hline$<0.94$ & $\$ 1.387$ & $\$ 9.735$ & $\$ 30.151$ & \\
& $(0.232)$ & $(0.187)$ & $(0.193)$ & \\
$0.94-0.97$ & $\{13,269\}$ & $\{13,572\}$ & $\{13,812\}$ & $\{40,653\}$ \\
& $\$ 7.282$ & $\$ 28.959$ & $\$ 72.282$ & \\
$0.97-1.00$ & $(0.185)$ & $(0.195)$ & $(0.215)$ & \\
& $\{7,739\}$ & $\{5,227\}$ & $\{3,018\}$ & $\{15,984\}$ \\
$1.00-1.03$ & $\$ 18.806$ & $\$ 43.656$ & $\$ 88.001$ & \\
& $(0.198)$ & $(0.206)$ & $(0.221)$ & \\
$1.03-1.06$ & $\{9,099\}$ & $\{5,886\}$ & $\{2,988\}$ & $\{17,973\}$ \\
& $\$ 37.483$ & $\$ 61.743$ & $\$ 105.474$ & \\
$\geq 1.06$ & $(0.218)$ & $(0.217)$ & $(0.228)$ & \\
& $\{8,827\}$ & $\{5,789\}$ & $\{2,839\}$ & $\{17,455\}$ \\
& $\$ 59.983$ & $\$ 82.572$ & $\$ 124.203$ & \\
& $(0.243)$ & $(0.231)$ & $(0.236)$ & \\
Subtotal & $\{7,155\}$ & $\{4,865\}$ & $\{2,694\}$ & $\{14,714\}$ \\
\hline
\end{tabular}

The cross-sectional time to expiration ranges from 8 to 360 days, with an average of 114.6. The free interest rate $r$ ranges from 3.89 to 6.31, with an average of 5.4, and the annualized payout return $d$ ranges from 0.82 to 2.38 , with an average of 1.49. At-the-money volatility implied by the Black-Scholes price ranges from 0.05 to 0.40 , with an average of 0.20 .

Tab. 2 - Sample properties of S\&P 500 index options 


\begin{tabular}{|c|c|c|c|c|}
\hline \multirow[b]{2}{*}{ Parameters } & \multirow{2}{*}{$\begin{array}{c}\text { All } \\
\text { Options }\end{array}$} & \multicolumn{3}{|c|}{ Days-to-expiration } \\
\hline & & $<60$ & $60-180$ & $>180$ \\
\hline$\overline{a^{A}}$ & 0.1837 & 0.1842 & 0.188 & 0.1714 \\
\hline & $(0.1059)$ & $(0.138)$ & $(0.0856)$ & $(0.0449)$ \\
\hline$b^{A}$ & 492.505 & 486.018 & 484.213 & 537.148 \\
\hline & (369.137) & (417.325) & (329.729) & (333.842) \\
\hline$q^{A}$ & 1.1255 & 1.1248 & 1.1287 & 1.1148 \\
\hline & $(0.2873)$ & $(0.3028)$ & $(0.3023)$ & $(0.2088)$ \\
\hline$a^{B}$ & 0.2046 & 0.2124 & 0.204 & 0.1857 \\
\hline & $(0.1595)$ & $(0.2329)$ & $(0.0798)$ & $(0.0533)$ \\
\hline$b^{B}$ & 516.737 & 508.626 & 510.554 & 558.225 \\
\hline & (402.469) & (473.003) & (338.878) & (354.997) \\
\hline$q^{B}$ & $\begin{array}{l}1.1288 \\
(0.9796)\end{array}$ & $\begin{array}{c}1.106 \\
(1.4704)\end{array}$ & $\begin{array}{l}1.152 \\
(0.3925)\end{array}$ & $\begin{array}{l}1.1286 \\
(0.2167)\end{array}$ \\
\hline SSE & 18.026 & 9.468 & 19.492 & 37.551 \\
\hline $\begin{array}{l}\text { Average out-of-sample percentage } \\
\text { errors }\end{array}$ & $-0.52 \%$ & $0.96 \%$ & $-0.57 \%$ & $-4.20 \%$ \\
\hline Nr. of observations & $\{197.903\}$ & $\{79.995\}$ & $\{68.330\}$ & $\{49.578\}$ \\
\hline
\end{tabular}

Tab. 3 - Implied parameters, in-sample and out-sample fits under maturity-based approach 